\title{
A escuta clínica: análise da linguagem simbólica de pessoas com estomias intestinais
}

\author{
Clinical listening: analysis of the symbolic \\ language of people with intestinal ostomy
}

\section{Priscila da Silva Antonio' 1 (1) Valéria Bertonha Machado ${ }^{2}$ (c) Francisco Moacir de Melo Catunda Martins ${ }^{3}$ (b)}

\begin{abstract}
1Autora para correspondência. Universidade de Brasília (Brasília). Distrito Federal, Brasil. priscilantonio@gmail.com
\end{abstract} 2-3Universidade de Brasília (Brasília). Distrito Federal, Brasil. valeriabert@gmail.com, fracatmartins@icloud.com

RESUMO | INTRODUÇÃO: O corpo pode ser compreendido a partir de uma perspectiva simbólica; por representações que abarcam a linguagem, em especial, a simbólica, cuja escuta atenta é importante para o entendimento da dimensão do sofrer. OBJETIVO: Analisar o emprego dos verbos páthicos (querer, poder e dever) na fala quotidiana de pessoas com estomias para compreensão do processo mental e da experiência vivida. MÉTODO: Estudo clínico-qualitativo, dados coletados por entrevistas abertas, submetidas à análise temática. Os sujeitos foram seis pessoas com estomia intestinal em acompanhamento em um hospital Universitário, no Brasil. Critérios de inclusão: ser usuário do serviço de estomaterapia do hospital em questão; apresentar estomia intestinal (definitiva ou provisória); aceitar participar do estudo; assinar o Termo de Consentimento Livre e Esclarecido; ser maior de 18 anos. Critérios de exclusão: não se sentir em condições físicas e/ ou psíquicas para participar. Pesquisa aprovada pelo CEP da Faculdade de Ciências da Saúde da Universidade de Brasília, sob o ofício de $n^{\circ}$ 033/12. RESULTADOS: Da análise emergiram duas categorias: 1) O corpo biológico: a experiência vivida no corpo efetivo material e, 2) O corpo vivido: a experiência vivida e sentida no corpo erótico-libidinal. CONSIDERAçÕES FINAIS: Em todos os casos apresentados os verbos páthicos se fizeram presentes marcando o movimento vivido. O método qualitativo permite a significação da linguagem ordinária configurando possibilidades para a praxis do cuidado.

PALAVRAS-CHAVE: Estomia. Pesquisa qualitative. Estudo clínico. Psicanálise. Saúde mental.
ABSTRACT | INTRODUCTION: The body can be understood from a symbolic perspective; through representations that embrace language, especially symbolic, whose attentive listening is important for understanding the dimension of suffering. OBJECTIVE: This article aims to analyse the modal verbs will, power and duty in ostomized people everyday speech, in order to understand the mental process and the lived experience. METHOD: In this clinical-qualitative study, the data were collected through open interviews, submitted to thematic analysis. The subjects were six people with intestinal ostomy being followed up at a University hospital in Brazil. Inclusion criteria: being a user of the stomatherapy service of the hospital in question; having an intestinal stoma (permanent or temporary); accept to participate in the study; sign the Free and Informed Consent Form; be over 18 years old. Exclusion criteria: not feeling physically and / or psychically fit to participate. Research approved by the CEP of the Faculty of Health Sciences of the University of Brasília, document $n^{\circ}$ 033/12. RESULTS: From the analysis two categories emerged: 1) The biological body: it deals with the experience lived in the material effective body and, 2) The lived body: it treats experience lived and felt in the erotic-libidinal body. FINAL CONSIDERATIONS: In all the cases presented, the modal verbs marked the living movement. The qualitative method allows the signification of the ordinary language configuring possibilities for the praxis of the care.

KEYWORDS: Ostomy. Qualitative research. Clinical study. Psychoanalysis. Mental health. 


\section{Introdução}

Considerando que a clínica é marcada pelo sofrer, neste estudo abordaremos o sofrimento de pessoas com estomia intestinal que padecem, não apenas, diante da luta travada entre a vida e a morte, ou das limitações físicas de seus corpos, mas também em razão da mudança mutiladora do estoma, vocábulo este advindo do grego, significando abertura; a qual permite uma troca entre os meios interno externo. Tal orifício, localizado no ventre, possui finalidade excretora. Vale ressaltar que em estomias intestinais provisórias a causa mais comum se dá por traumas abdominais; já em permanentes, o câncer colorretal (Crema e Silva, 1997; Mirand et al., 2014).

A escuta clínica será demonstrada através da leitura do uso dos verbos páthicos 'querer', 'poder' e 'dever'; que sob o escopo de Weizsäcker, são necessariamente humanos (Weizsäcker, 1958). No que tange à categoria páthica, que diferentemente da classificação linguística recai sob o termo 'modal', os verbos supracitados não apenas modalizam a frase, provocando mudança e movimento, mas também expressam questões do Eu, ou seja, da existência humana (Antonio, 2016; Antonio et al., 2019).

A partir de uma análise mais detalhada, observa-se que 'poder', por exemplo, se subdivide em categorias, alcançando dois significados, quais sejam: a) natural (poder por capacidade, diminuído pela doença, a qual exige por parte de quem a sofre uma readaptação a uma nova condição de saúde); e b) deôntico (poder como permissão, caracterizado pela liberdade, cuja maior precisão seria alcançada pelo construto 'permitir', expressamente, a si mesmo (Antonio, 2016; Antonio et al., 2019).

Não diferentemente de 'poder, o verbo 'dever' apresenta ambos sentidos expostos no parágrafo anterior, sendo na perspectiva natural 'dever como necessidade' (como exemplos, citamos as necessidades humanas básicas de nutrição, oxigenação, hidratação, etc) e 'dever como obrigação' (do latim dever; dívida ou débito. Desta forma, o sollen' é bem presente nos conflitos humanos em que o dever imposto pelo próprio sujeito é maior até do que as exigências sociais. Expressões como "devo ser forte", "devo vencer na vida", geram extrema angústia, uma imputação obrigatória cuja origem é identificada no interior do indivíduo (Antonio, 2016; Antonio et al., 2019).

Concernente ao 'querer', como força impulsora de uma determinada ação, trata-se de um verbo do consciente humano, lembrando que aquele que quer não tem dúvidas a respeito. Neste caso, a vontade se faz inabalável, não reconhecendo obstáculos. Isto dito, frente ao exposto questiona-se: como fazer uma escuta clínica que valorize o processo do pensamento dos pacientes?

Macêdo et al. (2018) destacam a importância da escuta clínica na produção de novos significados e, consequentemente, novos modos de sentir, pensar e agir. Nesta perspectiva, este estudo objetiva analisar o emprego dos verbos páthicos 'querer', 'poder' e dever' na fala quotidiana de pacientes com estomias para a compreensão do processo mental e a experiência vivida.

Cremos que esta técnica inovadora, de escuta, poderá ser utilizada em outras situações clínicas, mesmo àquelas em que o sofrimento dos pacientes não esteja relacionado ao corpo biológico (Dejours, 2001).

\section{O percurso metodológico}

Trata-se de um estudo descritivo de natureza qualitativa, sendo capaz de incorporar o significado e a intenção das ações, das relações e das estruturas sociais, tanto no seu advento, quanto na sua transformação, como construções humanas significativas, ou seja, tem o objetivo de aprofundar percepções e vivencias dos sujeitos em detrimento da quantidade dos relatos (Minayo, 2014; Antonio, 2016).

O pesquisador não é neutro, mas participa, compreende e interpreta o processo. Este é um método interativo entre os envolvidos de forma que o processo relacional permita a construção de novos significados. Desta forma, o contexto desta investigação se dá na dinâmica das relações, em ato, como na clínica. O método qualitativo também engloba a descrição dos dados de forma que a cena possa ser compartiIhada e compreendida por pessoas que não participaram do processo (Bassora e Campos, 2010).

1 Do alemão, significa "dever como obrigação", um imperativo. Este termo é utilizado por Freud (1923) para exemplificar o Supereu crítico. 
Mais especificamente, utiliza-se o método clínico-qualitativo. Este método possui algumas características, além do contexto clínico particular. Pois não é apenas um instrumento do conhecimento, mas uma prática. O clínico se preocupa com a ética da prática, de uma situação particular, e tem a preocupação com a ação reparadora desta ação (Antonio, 2016). Desta forma, o método clínico apresenta de antemão conhecimento teórico e prático, ou seja, "vivência do campo de estudo e de possíveis teorias que possam ser aplicadas no desenvolvimento do estudo, preservando assim a natureza teórica e prática como pontos simultâneos de partida" (Bassora e Campos, 2010, p.754).

O estudo em questão apresenta as prerrogativas inovadoras do método clínico-qualitativo destacadas nas literaturas citadas, uma vez que a escuta clínica e sua interpretação será feita via verbos páthicos. Uma teoria defendida por nós, que poderá ser utilizada por diferentes categorias de profissionais da saúde. Uma reconstrução que parte de uma composição teórica que se utiliza da psicanálise, da linguagem e da indução clínica que explora todos estes conhecimentos para a construção do novo.

Furegato (2018) ressalta a preocupação da Organização Mundial de Saúde na promoção do bem estar mental. Mais ao detalhe, a autora focaliza que o cuidado de enfermagem seja centrado na pessoa e que os profissional tem o desafio de perceber e intervir na atenção básica, procurando conhecer novas abordagens. Este estudo vai ao encontro desta necessidade, uma vez que traz à tona a saúde mental no contexto cotidiano do homem comum, que sofre por origens não psiquiátricas.

Becker (2018) também ressalta em seu estudo a necessidade de condutas ampliadas na saúde que vão de encontro com a pessoa e a sua integralidade, reconhecendo que em sua maior parte, estas ações têm sido mais tecnicistas.

Diante do exposto, que o leitor não se surpreenda ao ver conceitos psicanalíticos como a projeção e a negação serem utilizadas na leitura do material analítico, além da valorização dos significados conscientes e inconscientes advindos destes processos de defesa.

Desse modo, o estudo clínico-qualitativo é apropriado para abordar o objeto deste estudo considerando-se a subjetividade do fenômeno humano e a riqueza dos atos de fala, demonstrando como a narrativa não se dissocia do sentido e como o refinamento da escuta auxilia na prática clínica trazendo benefícios tanto para pacientes, quanto para profissionais.

\section{O Ambiente}

O ambiente específico do estudo foi um serviço ambulatorial de estomaterapia, localizado em um Hospital Universitário no Brasil, finalizado em junho de 2016.

\section{Os Colaboradores}

A pesquisa partiu de uma demanda do serviço em questão, desta forma o convite à participação foi realizado mediante ao encaminhamento do próprio serviço, assim, foram convidados pacientes usuários da referida unidade de saúde, constituído por seis pessoas com estomia intestinal definitiva. Todos com idade acima de 18 anos e parte do rol de pacientes usuários do serviço de estomaterapia mencionado.

Após o aceite, todos os pacientes que passaram a participar do estudo e foram denominados colaboradores. Foram feitos os esclarecimentos sobre a finalidade da pesquisa; o direito de se recusarem a participar; a participação espontânea com liberdade para desistência em qualquer fase do estudo sem sofrer qualquer prejuízo ou dano; e a garantia de anonimato.

Após o aceite, foi solicitada a autorização, por escrito através do Termo de Consentimento Livre e Esclarecido de acordo com as normas da Resolução do Conselho Nacional de Saúde no 466 (Brasil, 2012).

O projeto em estudo foi apresentado e aprovado pela Comissão de Ética em Pesquisa da Faculdade de Ciências da Saúde da Universidade de Brasília, sob o ofício de $n^{\circ} 033 / 12$.

Os colaboradores foram informados que as entrevistas seriam gravadas para facilitar o processo de transcrição e análise. Após a concordância procedeuse a gravação durante o atendimento a cada colaborador. Para garantir o anonimato dos colaboradores utilizamos nomes fictícios. 


\section{A coleta das informações}

Para a coleta das informações, utilizamos a entrevista não diretiva, pois o contexto da coleta das informações foi o acolhimento no ambiente hospitalar, de forma individualizada em local reservado. Esta técnica é originária de Freud o qual instrui seus leitores como proceder no início do tratamento. Segue as instruções de Freud (1913, p.140): "Deixar que o paciente fale quase o todo o tempo e não explicar mais do que o absolutamente necessário para fazê-lo prosseguir no que está dizendo".

Esta forma de coleta das informações permite que o informante fale livremente e espontaneamente, permitindo ao investigador captar o que é mais relevante, ou seja, os aspectos que vêm à mente e àqueles temas insistentemente repetidos, sem qualquer interferência do pesquisador. Desta forma, o entrevistado tem a possibilidade de discorrer o tema proposto, sem respostas ou condições prefixadas pelo pesquisador. O pesquisador não formula perguntas, apenas o dirige, facilitando o processo (Antonio, 2016). O entrevistado, Segundo Oliveira (2017), fala o que lhe vem à mente a partir da pergunta clássica dos atendimentos em saúde: Como vai você? (Martins, 2005).

Os pacientes foram informados do acolhimento e do estudo durante uma das reuniões da Associação dos Ostomizados regional. Aqueles que demonstraram o interesse em ser ouvidos poderiam agendar um horário no ambulatório. Foi informado, também, que o atendimento seria realizado mesmo àqueles que sentissem a necessidade do acolhimento e que não quisessem participar da pesquisa. Apenas uma paciente foi atendida sem participar do estudo.

\section{Análise Temática das Entrevistas}

As entrevistas foram transcritas na íntegra e posteriormente analisadas e interpretadas, utilizando-se a análise temática segundo o referencial de Minayo (2014).

Para esta autora, o objetivo da análise são os núcleos de sentido. Para tanto, passamos por três fases durante a leitura do material analítico: 1) pré-análise: fase de organização do material; 2) exploração do material: objetiva o núcleo da compreensão do texto a partir da transformação dos dados brutos; e 3) tratamento dos resultados: nesta faze consistem interpretações prenunciadas pela teoria e inferências do pesquisador que servem de base para outras análises.

Minayo ressalta três finalidades da pesquisa qualitativa. A primeira delas, a compreensão dos dados, seguida pela resposta às perguntas do estudo, por fim ampliar o conhecimento do assusto do estudo em articulação com o contexto ao qual se integra (Minayo, 2014). Cremos também na finalidade da validação da preposição teórica que somente em um estudo prático se pode verificar.

\section{Apresentação e análise dos dados}

O estoma em si não caracteriza uma doença. Trata-se de uma deficiência física provocada por outra patologia de base. O termo deficiência significa, segundo os dicionários, falta; lacuna; imperfeição; insuficiência. Desta forma, deficiente seria todo aquele que tem deficiência, que é ou está incompleto e/ou imperfeito (Michaelis, 1998). Assim somos todos nós, incompletos sempre em busca de algo faltante. O que se pretende enfatizar neste estudo faz parte de todos os humanos, páthicos, que sofrem em seus dilemas na caminhada da vida em busca de algo.

Os exemplos apresentados são de pessoas com estomias, pelo motivo do grande sofrimento vivido em uma situação particular pouco explorada pelos estudiosos da mente, embora esta leitura se estenda a todos os humanos sofredores. Nestes casos específicos, o verbo poder como capacidade natural está muito diminuído, sendo esta a queixa predominante dos colaboradores. Nos casos analisados, o câncer foi a principal causa. Apresentamos ao leitor seis casos de pessoas com estomia intestinal definitiva, apenas Marta apresenta duas estomias: uma intestinal e outra urinária. As informações dos colaboradores, consideradas importantes, estão expostas no quadro 1 para que o leitor tenha dimensão do sofrimento vivenciado por eles.

A acolhida era, geralmente, realizada no ambulatório da instituição, mas houveram situações em que os colaboradores estavam debilitados e foram internados (como nos casos da Luíza, do Pedro e da Ana), desta forma, foi-nos solicitado para que nos dirigíssemos até a clínica (cirúrgica ou médica) e assim se fez. 
Quadro 1. Informações dos pacientes colaboradores do estudo, conforme idade, patologia de base, tempo de estomia e característica quanto a permanência do estoma

\begin{tabular}{|c|c|c|c|c|}
\hline Nome & Idade & $\begin{array}{l}\text { Patologia de } \\
\text { base }\end{array}$ & Tempo de estomia & $\begin{array}{l}\text { Característica quanto a } \\
\text { permanência do estoma }\end{array}$ \\
\hline Marta & 61 anos & Câncer & $\begin{array}{c}6 \text { meses (apresenta } \\
\text { urostomia e colostomia). }\end{array}$ & Definitivo \\
\hline Renata & 40 anos & Câncer & 4 anos & Definitivo \\
\hline Pedro & 19 anos & Câncer & 6 meses & Incerto \\
\hline Rute & 83 anos & Câncer & $\begin{array}{l}\text { Aguardando a cirurgia para } \\
\text { recolocação do estoma, } \\
\text { agora definitivo. }\end{array}$ & Definitivo \\
\hline Luíza & 22 anos & $\begin{array}{l}\text { Retocolite } \\
\text { ulcerativa }\end{array}$ & 2 dias & Definitivo \\
\hline Ana & 36 anos & $\begin{array}{l}\text { Câncer/ } \\
\text { retocolite }\end{array}$ & 3 meses & Definitivo \\
\hline
\end{tabular}

(Antonio, 2016).

Submetemos o corpus discursivo à técnica de análise temática na qual levantamos o significado e o uso dos verbos páthicos 'querer', 'poder' e 'dever'. Do produto da análise temática emergiram duas categorias:

1) O corpo biológico e 2) o corpo vivido.

\section{Categoria 1 - 0 corpo biológico}

\section{Verbo: Poder como capacidade natural}

Nesta categoria nota-se o poder de realizar atividades da vida cotidiana diminuído, sendo esta a queixa predominante dos pacientes. Os núcleos de sentido emergidos das falas foram: "não posso", "não é normal", "não podia", "acabou pela doença”, "não dou conta".

Existem duas situações estereótipas para pessoas deficientes: 1) positivas e 2) negativas. No estereótipo positivo, a coragem. Na segunda situação, do estereótipo negativo, a dificuldade, pela diminuição da capacidade, em fazer as coisas (Antonio, 2016). No caso dos estomizados, a deficiência muitas vezes é "invisível", por ficar por baixo da roupa, escondida no ventre. Esta deficiência se diferencia por ser adquirida, consequentemente, a pessoa com estomia deverá se readaptar ao corpo que já não é mais o mesmo, ajustando sua vida à esta deficiência decorrente de doenças muito graves e, não raro, crônicas (quadro 1); levando a queixas frequentes.
Iniciaremos esta discussão pela senhora Marta de 61 anos de idade. Marta, solicitou um horário no ambulatório e estava acompanhada da filha, carregando uma almofada. O motivo para se dirigir à sala de acolhimento era o fato de que, há 6 meses da cirurgia de colostomia, se recusava a prestar o autocuidado no estoma. Marta se recusava, inclusive, a olhá-lo. A dieta da paciente também estava comprometida, pois ela só comia o que considerava (por si) ser permitido, mesmo diante de todas as explicações de que poderia, deveria inclusive, variar sua dieta. A paciente estava irredutível. Negava que estivesse estável clinicamente. Vejamos o que Marta nos diz a respeito do estoma:

"[...] o que eu tô mais incomodada é porque no ponto da cirurgia ainda tá um pouco abusado porque eu não posso sentar firmado. [Marta].

A colaboradora sente que seu corpo não é mais o mesmo depois da cirurgia. Ela não sente segurança e tem medo que atividades cotidianas, mais comuns, afetem os pontos da cirurgia, daí diz que "não pode sentar firmado". Não se sente segura ao sentar. Notem que o verbo está no particípio passado firmado, ou seja, uma ação que está finda, descarregada de descargas pulsionais (Antonio, 2016). Marta tem muito medo das mudanças ocorridas em seu corpo, tem medo de comer quase tudo, mesmo os profissionais orientando que pode, no sentido de permissão, comer. Percebemos aqui o verbo páthico 'poder como capacidade' diminuído (não poder sentar firmada) junto ao movimento pulsional de negação. 
"Mas não é normal, eu senti que não é normal. E com 6 meses? Não já era pra tá bem melhor? [Marta].

Nesta queixa, Marta, reclama que seu estado de saúde não é normal. O não refere à negação (Laplanche, 2001). Como ela faz este diagnóstico de si mesma? Através dos sentidos. Ela sente, tem uma percepção de que não está bem. Marta nega e projeta na equipe de saúde. Vejamos mais o que disse ela nesta ocasião:

\section{"[...] fico imaginando [...] já vi passar tantos casos} feio [...] às vezes não é culpa nem dos médicos, que acontece. Acontece de ficar uma tesoura, ficar um pedaço de pano [...] já viu passar na televisão? Eu já vi! Por isso que eu falei pra ele. Eu quero que o senhor me corrige bem [...] não tô sarada direito a ponto de eu sentar apoiada, pra onde eu vou é com almofada".

[Marta].

Aqui a projeção fica ainda mais evidente no Eu somado ao predicado inacessível. A colaboradora projeta seus medos na cirurgia e na equipe de saúde. Na verdade tudo está bem com a cirurgia do estoma, a infecção é um outro problema de saúde, sem ligação com a estomia.

No texto "A negativa" Freud (1925) nos alerta para o dinamismo da mente dos pacientes, cujas associações demonstram negar o conteúdo reprimido que vêm à consciência. Neste texto a projeção e a negação estão juntas, assim como em nosso caso clínico. Para Freud o pensamento negado é o que o paciente repudia. Freud diz: "Em nossa interpretação, tomamos a liberdade de desprezar a negativa e de escolher apenas o tema geral da associação" (1925, p.265). Nesta mesma página o exemplo citado, na íntegra, por Freud é o seguinte: "O Senhor pergunta quem pode ser essa pessoa no sonho. Não é a minha mãe" (Freud, 1925, p.265). Então a leitura de Freud é afirmativa: "é a mãe dele". Desta mesma forma ignoramos a negativa da colaboradora Marta quando disse "não é culpa dos médicos". Entendemos que o "não" é um "sim". Então, "é culpa dos médicos". Por isso projeta na decisão desta equipe em seus esforços para melhorar sua saúde e reclama da internação. Freud nos alerta de que este é um conteúdo de uma ideia obsessiva, um conteúdo reprimido.

Este é exatamente o que ocorreu com a colaboradora Marta. Houve uma separação da função intelectual do processo afetivo, o que a leva a negar que ocorreu tudo bem na cirurgia. Uma percepção da realidade em que a colaboradora põe para fora o que lhe é repugnante e projeta. Marta se nega sentir, palpar, cuidar do seu estoma. Para ela, esta abertura lhe é repulsiva. Em seu julgamento perceptivo, acredita que não está bem. Apresentamos mais um exemplo na declaração de Marta relacionada ao seu poder diminuído (o poder de fazer as coisas):

"Eu lembro que não sou mais mulher pra fazer nada. Nada, nada, nada, nada". [Marta].

O verbo está no presente do indicativo, em primeira pessoa. Uma sentença que ela nega e diminui sua existência à nada. Várias perdas, em virtude da doença, são relatadas. Marta conta algumas coisas que perdeu, pela doença, como não poder mais cuidar da terra (ela mora no campo) tudo se acabou, bem como sua vida:

"Tinha, mas acabou. Acabou por conta da doença, não tinha quem cuidasse. Terra, acabou tudo. Acabou pela

doença" [Marta].

Vejamos outro caso clínico, Renata de 38 anos. Renata tem duas estomias, uma urostomia e uma colostomia, originadas por um câncer que iniciou na tireoide. No primeiro encontro, contou-nos um pouco sobre sua trajetória desde que foi diagnosticada com câncer:

"[...] quando eu fui fazer uma cirurgia no hospital, eu já fiz dois tratamentos de iodo terapia, depois da cirurgia da tireoide. Inclusive no primeiro tratamento que eu fiz [...], a médica perguntou "você quer um remédio pra dormir, alguma coisa pra ajudar?" eu falei "não doutora, eu costumo ficar de olho aberto". [Renata].

Renata procurou o acolhimento porque está com medo. Medo de que o câncer volte. Ela não tem o poder de impedir a morte. Neste relato do seu primeiro tratamento, ela recusa a medicação para dormir. Nossa colaboradora recusa este tipo de medicação até hoje. Apesar de ter tratado o câncer, ela permanece com medo de dormir e não acordar, por isso costuma "ficar de olho aberto". Antes de voltarmos a este ponto motivador do movimento da colaboradora ao ambulatório, vejamos mais exemplos do 'poder como capacidade' diminuído nos afazeres da vida cotidiana:

"Eu não cuido da roupa, cozinho, isso tudo eu não dou conta porque assim, as condições também [...]". [Renata]. 
A expressão no presente "eu não dou conta" tem sinonimia ao verbo conseguir. $O$ poder diminuído de Renata é fonte de grande sofrimento. A colaboradora deve, no sentido de necessidade, se colocar nas mãos dos médicos. O poder diminuído é também representado na passividade diante do tratamento que lhe é oferecido, pois precisa (necessidade natural) deste. Vejamos o que ela disse:

"A médica fez uma colposcopia que era o único exame que podia mostrar [...] realmente eu já estava com um nódulo desse tamanho (faz o gesto) [...] por dentro [...] ela tirou parte e fez biópsia [...] ela disse "[...] vamos cauterizar". Aí me pediu pra comprar um produto, eu comprei. Não sabia se podia, se não podia, eu fui por ela. É claro, [...] você vai pela pessoa que você está confiando. Você acredita na pessoa. Comprei, quando ela cauterizou, explodiu". [Renata].

Renata projeta seu sentimento de reação, de ousadia frente à injustiça e ao descaso sofridos, que frustrou suas esperanças ao bom andamento do tratamento. Ela se compara à situação brasileira, que em geral é passiva diante das questões políticas, mas que ultimamente tem protestado nas ruas. Nossa interpretação é de que Renata gostaria de protestar, de gritar nas ruas tudo o que tem sofrido durante estes anos:

"Aí...se eu vou esperar uma consulta daqui seis meses? [...] a população vai às ruas" [Renata].

Esta é uma fala de si mesma, ela é quem sente a necessidade de protestar:

"Aí a gente vai vendo, a gente está numa situação que não tem mais para onde correr. Então, você vê, eu fiz o tratamento [...] perdi bexiga, perdi reto [...] é, perdi tudo!".

"Porque que a população está fazendo isso? Porque explodiu, de uma forma que a pessoa vai indo e não segura mais".

A população brasileira ousou reclamar, Renata quer fazer o mesmo. Esta fala é uma identificação projetiva. Ela é quem quer por tudo pra fora porque está a ponto de explodir, por isso usa o mesmo termo do que aconteceu com ela no atendimento frustrado: o câncer explodiu.

\section{Verbo: Dever como necessidade natural}

O dever como necessidade natural é também relacionado ao corpo efetivo material, ou corpo biológico (Dejours, 2001). Este verbo representa a necessidade deste corpo que depende de cuidados para trazer qualidade de vida, conforto e segurança, dentre tantos outros, ou seja, das necessidades humanas. Por esta razão, as necessidades de oxigenação, hidratação, nutrição, sono e repouso podem ser incluídas neste verbo.

Os núcleos de sentido são: "desidratação", "alimentação", "ter que tira" (sentido de operar), "precisar internar", "precisando ficar", "vai te internar", "precisa fazer", "não resiste", "não perguntei". Vejamos a fala do colaborador Pedro:

"É que eu praticamente tava entrando em depressão por causa dessa estomia [...] é por causa da alimentação que eu desidratei agora e tô tomando soro aqui, é isso."[Pedro].

A necessidade de hidratação foi o que levou Pedro à internação. A estomia traz um impacto grande na vida dos pacientes. Pedro tem uma ileostomia, o que dificulta ainda mais a absorção dos nutrientes além da perda de eletrólitos. Pedro não pode comer tudo o que quer, nem a quantidade que quer, ele precisa de cuidados. O sintoma de Pedro do corpo biológico, foi facilmente identificado e tratado no hospital, mas notem que o paciente refere dois sintomas. Um relacionado ao corpo efetivo material e outro ao corpo erótico libidinal (Dejours, 2001). A depressão, é listada em primeiro lugar. Para ele a depressão é a causa da desidratação. Foi por causa dela que Pedro não se cuidou como deveria. Mas a grande vilã de Pedro também não é a depressão, mas a estomia. Esta sim, é a causa de todas as suas infelicidades sofridas:

"[...] aí veio essa estomia que é muito difícil, né? E...tem que trocar toda hora, e a alimentação que é muito é pouca, né? Em relação as coisas que pode comer, as refeições que é muito variada aí é isso". [Pedro]. 
Pedro resume sua vida ao estoma. Vive a barriga e a negação e a projeção são evidenciadas (Laplanche, 2001). Na projeção, a afirmação acima de que todas as dificuldades enfrentadas na vida, são culpa do estoma que, obviamente, ele não reconhece como parte de si quando diz "essa estomia que é muito difícil" e todos os cuidados necessários, muito inconvenientes, que ele tem que realizar, "tem que trocar toda hora a alimentação que é muito pouca". Pensamos que Pedro, na idade de 19 anos, tem o metabolismo acelerado e sente bastante fome. Quanto a viver o estoma, a fala a seguir:

"Tenho. Só isso, basicamente o todo da minha vida". [Pedro].

Pedro, assim como os demais pacientes precisam por a vida em movimento. Ao final da conversa, ele reflete um pouco, agradece e diz que é a primeira vez que é abordado desta maneira no hospital. Esta é mais uma evidência da importância da escuta clínica.

Rute é uma senhora de 83 anos de idade. Ela já teve uma colostomia anteriormente, fez a cirurgia de reversão, mas o câncer voltou e ela fará uma nova cirurgia de recolocação do estoma definitivo. Rute estava calma, muito bem cuidada, acompanhada por duas filhas. Ela relatou que sente a necessidade de recolocar o estoma, pois está com sangramentos e grande incômodo. A colaboradora Rute tem esperanças na cirurgia. Vejamos algumas de suas palavras:

"A Dra A. falou que isso só vai parar depois que tirar tudo [...]. Porque a cirurgia que fez, fez a biópsia e disse que a cirurgia não tinha ficado nada, né? Mas voltou de novo, e no mesmo lugar, né? Aí vai ter que tirar". [Rute].

Rute precisa fazer a cirurgia para ter maior qualidade de vida. Ela vai remover todo o intestino grosso, talvez parte do delgado. O incômodo, ao qual ela se refere, é uma secreção na região anal. Ela fez a última cirurgia há seis meses. Este tratamento é muito específico, os pacientes precisam de constantes monitoramentos. Por isso ela disse "estava precisando ficar". Notem que o verbo está em in fieri, ou seja, em andamento. Um atividade com carga pulsional (não tão intensa quanto no presente do indicativo, in posse, mas está presente). A cena está em andamento. Ela está aguardando a cirurgia, em paz.
"Pois é cheguei com aquela lembrança que ia voltar logo, mas no meu caso, tava precisando ficar. Por que lá eu não ia saber que remédio eu ia tomar" [Rute].

A necessidade da cirurgia e do estoma é indubitável, um dever como necessidade natural. Esta percepção também foi relatada pela colaboradora Luíza:

"[...] A Dra, falou que era pra eu vir até aqui consultar com o proctologista [...]. Chegando aqui ele falou: não, a gente vai te internar aqui porque você precisa fazer um exame. [...] ele fez o exame, [...]. Quando ele viu a situação do meu intestino, ele falou: se a gente não fizer a cirurgia agora, a Luíza não resiste nem mais três dias.

Aí o que aconteceu? A gente correu pra cirurgia, e ele sempre do meu lado, só não me explicou nada". [Luíza].

Na fala da colaboradora Luíza a urgência da cirurgia é marcada. Não há tempo a perder. Ela sabe que precisa da cirurgia. Ela reconhece o esforço do médico que não a abandonou e salvou sua vida, mas a negação vem em seguida "só não me explicou nada". Na verdade Luíza não é tão passiva assim e projeta na queixa de que o médico não explicou nada a ela sobre os procedimentos a serem tomados. Ela acordou com o aparelho coletor já instalado. Seria esta fala de Luíza uma negação? O que ela nega? A primeira impressão desta colaboradora, no verbo poder por capacidade, ela parecia que aceitava de tão bom grado a estomia, alegando a possibilidade de vida. O que será que se esconde neste detalhe da fala de Luíza? É possível que nossa colaboradora não queria saber sobre o seu prognóstico médico, uma negação. Vejamos um pouco mais a fala de Luíza:

"Só disse, a gente vai fazer a cirurgia. Eu também não falei nada, não perguntei porque [...] médico é médico.

Sempre sabe o que tá fazendo, né? Que tá fazendo o melhor pra você".

Inclinamo-nos a pensar que Luíza preferiu não saber que estava à beira da morte antes da cirurgia. Por isso a negação aparece marcada na fala. 


\section{Categoria 2 - 0 corpo vivido: trata experiência vivida e sentida no corpo erótico-libidinal}

\section{Verbo: Dever como obrigação moral}

Nesta categoria será dada ênfase às obrigações (deveres) de ordem moral, o supereu crítico é fortemente marcado nas falas dos nossos colaboradores, sendo ideal do Eu também enfatizado (Freud, 1925). Os núcleos de sentido são: "tentar não passar", "segurei", "não sou de desesperar", "nunca tomei nenhum remédio", "não fico reclamando, choramingando", "as pessoas parecem que estão cegas", "olha pra mim", "vou continuar a mesma pessoa", "criei treze filhos". Prossigamos aos exemplos clínicos:

A colaboradora Renata se preocupa com a família, no sentido de poupar seus familiares do seu sofrimento. O verbo dever aqui é o "dever ser forte". Ela é severa consigo mesma, não se permite nem mesmo um calmantezinho para aliviar sua tensão, Vejamos o que ela me disse:

"Então você tenta não passar, tenta não... as pessoas que estão em volta. No período que eu tive estes problemas eu segurei muito porque minha família é aquela família, tipo, quando você fala uma coisa a pessoa desespera, sabe?". [Renata].

Renata se reconhece como sendo mais forte que sua família. Ela passou por problemas seríssimos de saúde, tem uma filha pequena e ainda consegue manter a ordem da sua casa. Renata incorporou à risca o estereótipo do deficiente físico, a coragem. Mas agora, ela está cansada, exausta. Renata nos procurou porque precisava desabafar, jogar pra fora, como ela mesma disse:

"Eu não sou assim, pode estar caindo o mundo, eu não sou de desesperar, não. Então, eu segurei muito isso, eu segurei muito [...] Nunca tomei nenhum remédio, nenhum calmante, nada. Então, eu sinto que eu preciso, como vou dizer? Jogar isso pra fora". [Renata].

Renata quer ser ouvida, cuidada sendo esta a motivação de sua ida ao ambulatório. Renata se impôs um dever cuidar de tudo e de todos, como uma rocha. Sempre calma, sempre forte. Ela reconhece o tratamento, através do qual possibilitou que continuasse viva, mas vive um conflito entre a raiva de estar doente, e a família não reconhecer sua fragilidade. Ainda tem a dívida da gratidão pela oportunidade de poder receber este tratamento. Ela reconhece que seria difícil sobreviver depois de tudo o que passou (tantas complicações e cirurgias), mas duas bolsas é demais:

"Graças a Deus eu tenho oportunidade de fazer o tratamento, mas isso mexe muito com a gente, mexe muito psicologicamente, fisicamente. Tem hora que você olha [...] eu fiz a cirurgia e coloquei as duas bolsas, não é?". [Renata].

"Não fico reclamando, choramingando [...] não fico, sabe?. [Renata].

A colaboradora sente um peso pelo dever imposto a si mesma de carregar sozinha a sua dor, ao mesmo tempo sente culpa. Desta forma não se permite nem mesmo tomar um medicamento para aliviar este sintoma. Porque a recusa da paciente em aceitar um remédio aliviador, anestesiador de sua dor? Isso nos remete ao conflito psíquico entre a dor e o prazer na dor. Neste caso, o ganho secundário da doença descrito por Freud (1901-1905). Podemos observar, também neste caso, uma ambiguidade de sentimentos: ao mesmo tempo que Renata decide segurar sozinha a sua dor, ela quer o cuidado e o olhar da família. Renata escolhe o verbo segurar para expressar o que está sentindo. Segurar pode ser visto como dar suporte, este é o nosso palpite que Renata acaba por aceitar, respondendo afirmativamente diante da nossa pergunta se ela se sente o esteio da família. Renata cobra muito de si e também dos outros. Vejam o que ela disse:

"Lá em casa, de certa forma, mesmo eu passando por tudo isso, não sei porque...eles correm todos lá pra casa, pra minha casa [...] não tenho coragem de dizer: não eu não posso atender. Eu acho que eu ficaria pior do que não fazendo. Às vezes por coisas tão pequenas, sabe, coisinhas...e as pessoas parecem que estão cegas, sei lá. Não sei como é [...] parece que estão tampadas [...] é isso". [Renata].

Renata tem este papel de esteio da família que ela não delega a ninguém. $O$ ganho secundário é o reconhecimento de ser forte e boa. Ao mesmo tempo, sente uma raiva interna em que as pessoas não veem o seu sofrimento. Renata fica indignada porque o seu problema é muito maior do que todos os que são levados à sua casa. Ela luta contra a morte e ninguém percebe isso? 
"Se tem uma coisa que... as vezes eu vejo as pessoas por tão pouco [...]. Minha família mesmo, reclama tanto. Às vezes dá vontade de mandar a pessoa para aquele lugar [...] porque, olha pra mim! ". [Renata].

Ao mesmo tempo, quando Renata cuida dos problemas dos outros ela esquece os seus próprios problemas e deixa de viver em função do seu próprio ventre. Isso a conforta:

"Eu procuro esquecer que eu tenho [...] que eu tenho duas bolsas penduradas na barriga [...] eu procuro esquecer isso [...] prefiro olhar para o outro do que olhar pra mim [...]". [Renata].

Falemos um pouco de Luíza, nossa colaboradora esperançosa pela vida. Luíza ama os pais e sente que tem uma dívida para com eles. O dever ser forte é marcado no depoimento de Luíza. Ela fala com firmeza, ao lado da mãe, que chora. Por amor aos pais e a família, que não a abandonam, ela renuncia o desespero e o sofrimento e decide ser forte, vencer na vida. Um ideal do Eu elevado. A menina modelo, forte, corajosa e que enfrenta todas as adversidades da vida. Luíza disse:

"Não vou me abater, de jeito nenhum, de forma alguma por causa disso aqui. Por esse novo... deixa eu ver [...] acessório, digamos assim". [Luíza].

"[...] vou continuar a mesma pessoa [...]. Eu sou muito brincalhona, eu gosto demais de palhaçada, vou continuar do mesmo jeito. [...] Pode ser que venha alguma adversidade na vida né? Que a gente nunca sabe, por isso aqui? Não. Mãe, para de chorar! Pelo que eu passei, assim, né?". [Luíza].

Luíza recusa veementemente se abater e diminui o estoma: "não vou me abater por causa disso aqui" - o isso, se torna pequeno ("só por causa disso") e chama o aparelho coletor, de acessório. Brinca e faz um Witz (ironia fina) com a bolsa, um "acessório" (objeto de desejo das mulheres) (Antonio, 2016). Ela tem algo maior, uma missão na vida, trazer alegria à família (fazer rir). Luíza está com grande potencia do Eu e sustenta a família, conforta até a mãe "Não. Mãe, para de chorar! Vou continuar a mesma". Recusa que o estoma seja um problema e o encara como solução. Solução para as limitações que tinha antes e se enche de esperança: um futuro melhor em que pode sair, se divertir. Nega fortemente a dura realidade, pois é forte e já passou por coisas muito piores.
Neste momento a mãe diz: "Parabéns Luíza, você é muito forte!" "Você ajuda muito". A filha ajuda os pais, por amor, alivia o sofrimento deles e nega o seu próprio. Por amor ela se impõe obstinadamente ser forte, vencer e ser feliz. Não pode, não deve e não se permite esmorecer. Tudo, por amor aos pais.

"Eu tenho apoio da minha família em peso. Minha mãe, o tempo todo do meu lado. Meu pai, todo mundo! Eu sempre vou ter eles do meu lado. Eu tenho esta certeza. Eu acho que é isso que me faz forte.". [Luíza].

Em contraste com os colaboradores que muito exigem de si com deveres a cumprir, em favor da família, dos amigos, dentre outros, Rute (colaboradora de 83 anos de idade) está apaziguada. Ela sente que cumpriu o seu dever e está tranquila diante dos frutos colhidos durante sua jornada na vida:

"Aí eu tô conformada, graças a Deus. Tô com a firmeza do nosso pai. Porque é só Ele que firma nóis. Então [...] eu estou com essa esperança. Criei 13 filhos, tudo em casa". [Rute].

A colaboradora Rute utiliza o verbo in esse "conformada". Ela está tranquila porque criou os 13 filhos. O esposo faleceu à 4 anos e como ela mesma disse: "os filhos já estavam todos criados". Ela tem uma grande família, que cuida dela e está sempre presente. Inclusive, ela estava acompanhada de três filhas, muito amorosas para com ela. A colaboradora contempla sua geração com a satisfação de ter cumprido sua missão, agora ela passa o bastão para as gerações futuras:

"Terceira geração [...] engraçado geração, né? Gente é importante, né? Nós somos muito importante". [Rute].

Rute aceita o seu dever de cuidar da casa e dos filhos, aceita o destino imposto pelo pai que não permitiu que as mulheres estudassem. Ela aceita este destino, por algo maior, sublimado. $\mathrm{O}$ amor a Deus que como um pai cuida dos seus filhos. Assim, pensamos que Rute se projeta nesta posição: ela aceita o destino e cuida dos seus filhos com amor. Uma "mãezona" que agora se sente apaziguada, locupletada.

\section{Verbo: Poder como permissão moral}

Este verbo marca a liberdade, o permitir-se dos pacientes. Ao contrário do dever e da dívida que pesam a existência, este verbo tem a característica de trazer a leveza, a brincadeira, a ousadia, o experimento. 
Sabemos que a liberdade em excesso pode conduzir à delinquência pelas ações de: quebrar, transgredir e infringir, por exemplo (Antonio, 2016). Os núcleos de sentido que marcam este verbo são: "poder sair", "me divertir", "poder trabalhar", "eu vou poder ter", "aproveitar a vida" e "fazer uma tatuagem na cicatriz".

Cremos que este movimento é uma prerrogativa para continuar a vida após o estoma. É necessário que o paciente experimente seu corpo, seu novo corpo. Partimos do pressuposto que a ousadia, o permitirse será libertador para a reinvenção da própria vida. Percebe-se que a maioria das pessoas com estomias não se permite nem ao menos desejar alguma coisa; como se estivessem condenadas a uma prisão dentro do próprio corpo que as tornam incapazes de querer.

O querer, último verbo a ser tratado neste estudo, é o verbo da força motriz para esta mudança, mas antes porém, é necessário permitir-se querer. Este é um dos desafios aos profissionais que cuidam de pessoas com estomias: trazer a criatividade, a ousadia, a permissão. O remédio a ser prescrito contra o sintoma da incapacidade e ao "não poder". Dentre os colaboradores do nosso estudo, Luíza e Pedro, os mais jovens são os que ousam querer alguma coisa. A força do jovem e a vitalidade parecem interferir diretamente na ousadia. Trata-se de um movimento mental que tem a capacidade de mudar um destino. Vejamos as palavras de Luíza:

"Normal pra mim é poder sair com as minhas amigas, me divertir, assim, poder ter uma vida mais normal, poder trabalhar [...] porque eu tenho muita vontade [...] de trabalhar". [Luíza].

Luíza traz em sua narrativa a normalidade cotidiana dos viventes, jovens como ela, e não de sobreviventes que vivem em função do estoma. Para este movimento é preciso permitir-se a si mesmo. Poder realizar as atividades de sair, se divertir e trabalhar, são coisas de viventes e não de doentes; estes verbos marcam o movimento. $O$ verbo de ação sair é o primeiro, simbolizando o movimento esperado.

"Estou fazendo faculdade de farmácia. Aí eu quero fazer minha faculdade e ter uma vida normal como todas as minhas amigas e eu creio que agora eu vou poder ter, né?". [Luíza].
Luíza espera um futuro melhor pela estomia. Ela não vê sua condição de "pessoa com estomia" como um problema, mas como solução para poder, finalmente, viver sua juventude. O verbo querer faz o cálculo com a ação já em movimento, com o verbo conjugado no gerúndio (fazendo), rumo aos seus objetivos de vida. O querer ter uma vida diferente e a dúvida se isso será mesmo possível, por isso ela nos devolve a pergunta "eu creio que agora eu vou poder, não é?". Ela quer algo que falta, por isso dizemos que este movimento é pulsionalizado.

Para esta concretização do querer, é preciso poder. Primeiro poder como capacidade, que ela já conseguiu através do estoma, depois, permitir-se moralmente querer, a ousadia (Antonio, 2016). O que move a paciente nesta busca é a esperança que ela tem de que será possível. A esperança é fundamental, sem ela, não há investimento. A jovem colaboradora sonha e tem esperança, isso lhe dá força e impulso para enfrentar as dificuldades que haverão pelo caminho. Luíza tem todos estes requisitos, por isso ela crê, espera e tem certeza que alcançará seu objetivo.

O segundo encontro com Pedro foi bem diferente do primeiro. Ele estava animado e cheio de sonhos. A ousadia e a vitalidade de um jovem, estava de volta. O estado clínico de Pedro não mudou, mas o movimento mental fez toda a diferença. E decide comemorar. Vai fazer o primeiro aniversário do estoma, junto com o seu de virada de uma década: 20 anos! A esperança brota em Pedro uma vontade de viver, de forma que ele vê o mundo diferente. O que mudou foi o seu olhar.

"É! Vou fazer 20 aninhos! Aí é isso né! Aproveitar a vida, agora. Depois de dois meses que colocar isso daqui pra dentro. Fazer meu umbigo de novo [...] até que vai dá pra botar pearcing, só que eu não vou botar (risos). Não (risos) aí eu vou fazer, eu acho que eu vou fazer uma tatuagem na cicatriz pra tampar. Aí é isso".

[Pedro].

Vejam como Pedro ousa. Ele faz um cálculo mental projetado para o futuro em que há possibilidade de fazer a cirurgia de reversão, faz planos para o que fazer com a cicatriz (uma tatuagem). Ele forma a imagem de como ficará o abdome após a cirurgia e modifica as ações no presente do indicativo. Sem esperança, não há motivos para desperdiçar energia pulsional (Antonio, 2016). Mas a esperança, faz com que este movimento valha a pena. Pedro ousa mesmo, até 
brinca em escolher qual regra quebrará para, desespero da sua mãe. Ele brinca e se diverte com a escolha entre o piercing e a tatuagem. Coisas de vivente!

Ao ser questionado sobre a queixa do encontro anterior, lembrando que foi internado por comer demais, o que não podia, e de como ele vai reagir no aniversário em que não poderá comer tudo o que quer, vejam a resposta de Pedro:

"Nem bolo de confeiteiro, nem salgado. Mas, tem presente!". [Pedro].

Ótima saída, não? Pedro permite-se ousar, criar e viver a vida com o que lhe é possível.

\section{Verbo: Querer como vontade voluntária}

Optamos por deixar o verbo querer por último não apenas pela sua grande importância para a mudança de um destino, um verbo impulsor da ação, mas também por ser um verbo do consciente humano. $O$ "querer" é voluntário. O verbo "querer" tem força impulsora, porque é um ato consciente, já refletido, calculado. Por este motivo, consideramos o verbo mais racional das categorias páthicas. Quanto mais consciente for a vontade, mais forte será o querer (Antonio, 2016). Os núcleos de sentido do verbo querer são: "vontade de viver", "força maior", "quero viver mais".

Finalizamos este tópico com a colaboradora Ana e sua vontade de viver. O 'poder como capacidade' está diminuído Ana sente que não vai aguentar. Apesar do seu querer fazer a quimioterapia ser tão forte, ao ponto de dizer que nada sentiu; agora percebe que seu corpo não está aguentando. Ana quer uma segunda chance de viver:

"Viver. Força de vontade de viver. A gente tem força de viver, mas quando você recebe uma notícia que tá com câncer a primeira coisa que vêm na sua frente é: Ai, eu vou morrer". [Ana].

\section{"A primeira coisa que vem na sua frente [...] parece que vem uma vontade de viver maior ainda vida [...] não sei te explicar, todo mundo tem vontade de viver, mas quando você está doente [...] alguma coisa parece que vem aquela força maior. Você quer viver mais". [Ana].}

Oliveira (2017) ressalta a importância do compartilhamento da experiência da doença em. Desta forma a escuta clínica é fundamental para a compreensão do que se passa na mente dos pacientes para que este cuidado vá ao encontro às suas reais necessidades. Ana quer viver e o verbo querer está no presente do indicativo, carregado de carga pulsional, conjugado na primeira pessoa do singular:

"Então é assim que eu sinto, quero viver mais". [Ana]

Ana quer viver hoje, no tempo onde se passa a vida, no presente do indicativo. Amanhã, veremos depois. Amanhã é outro dia.

\section{Considerações finais}

Este estudo privilegiou a escuta de pessoas com estomias intestinais em uma leitura do emprego dos verbos páthicos 'querer', 'poder' e 'dever'. A motivação para tal investigação, considerou a solicitação do próprio serviço ambulatorial de enfermagem em estomaterapia, em razão do grande sofrimento vivido em uma situação particular, pouco explorada pelos estudiosos da mente.

Do produto da análise, emergiram duas categorias, relacionadas aos verbos páthicos e aos processos de defesa, a saber: 1) O corpo biológico: experiência vivida no corpo efetivo material, ou corpo biológico; e 2) O corpo vivido: a experiência vivida e sentida no corpo erótico-libidinal.

Na primeira categoria, do corpo biológico, o 'poder como capacidade' diminuído, foi destacado pela colaboradora Marta na recusa em realizar o auto cuidado. Neste caso o estoma foi considerado a causa das suas dificuldades físicas. Luíza, ao contrário, atribui ao estoma a possibilidade de viver a sua juventude. Graças ao estoma, ela poderá sair de casa e ter uma vida social mais plena. Conclui-se que este mesmo verbo, visto por outro ponto de vista, pode modificar o curso vivido pelos pacientes.

Quanto ao corpo vivido (segunda categoria), o 'dever' é fortemente marcado na fala de Renata na cobrança a si mesma em "dever ser forte", que a leva ao sofrimento. Este mesmo verbo é visto sem qualquer exigência por Rute, apaziguada no sentimento de "dever cumprido". Ainda nesta categoria observa-se, o 'poder de permissão' na experiência compartilhada por Pedro em "quebrar das regras". Quanto ao querer, verbo do consciente humano, é expresso por Ana, que na luta contra a morte, decide viver. 
Apesar da compreensão de que os conflitos e sofrimentos humanos não se restringem aos verbos páthicos, cremos que sua análise pode servir como um grande instrumento na clínica no sentido de interpretação das falas dos pacientes, ou seja, uma escuta que valorize o processo do pensamento, contribuindo para a humanização do cuidado.

\section{Agradecimentos}

Agradecemos ao financiamento das agências: CAPES - Coordenação de Aperfeiçoamento de Pessoal de Nível Superior e a Decanato de Pesquisa e Inovação - da Universidade de Brasília. Ao professor Dejours, C. que contribuiu na discussão dos casos clínicos.

Este artigo é resultado de pesquisa aprovada para apresentação no $8^{\circ}$ Congresso Ibero-Americano em Investigação Qualitativa CIAIQ, realizado de 16 a 19 de julho de 2019 em Lisboa, Portugal.

\section{Contribuições dos autores}

Antonio, P. S. e Martins, F. M. M. C. participaram da concepção, delineamento, busca e análise dos dados da pesquisa, interpretação dos resultados, redação do artigo científico. Machado, V. B. participou do percurso metodológico, interpretação dos resultados e redação do artigo científico.

\section{Conflitos de interesses}

Nenhum conflito financeiro, legal ou político envolvendo terceiros (governo, empresas e fundações privadas, etc.) foi declarado para nenhum aspecto do trabalho submetido (incluindo mas não limitando-se a subvenções e financiamentos, participação em conselho consultivo, desenho de estudo, preparação de manuscrito, análise estatística, etc.).

\section{Referências}

Antonio, P. S. (2016). O estoma: investigação psicanalíticaexistencial do sofrimento psíquico e sua modalização (Tese de Doutorado). Universidade de Brasília, Instituto de Psicologia Clínica e Cultura, Brasília, DF, Brasil.

Antonio, P. S., Machado, V. B., \& Martins, F. M. M. C. (2019, julho). O corpo e a linguagem simbólica: análise dos verbos páthicos e seu uso na prática clínica. Atas do Congresso Ibero-Americano em Investigação Qualitativa, Lisboa, 8. Recuperado de https://proceedings.ciaiq.org/index.php/ CIAIQ2019/issue/view/28
Bassora, J. B., \& Campos C. J. G. (2010). Metodologia clínicoqualitativa na produção científica no campo da saúde e ciências humanas: uma revisão integrativa. Revista Eletrônica de Enfermagem, 12(4), 753-60. Recuperado de https://www.revistas.ufg.br/fen/article/view/5804/8499. doi: $10.5216 /$ ree.v12i4.5804

Becker, R. M., Heidemann, I. T. S. B., Meirelles, B. H. S., Costa, M. F. B. N. A., Antonini, F. O., ... Durand, M. K. (2018). Nursing care practices for people with Chronic Noncommunicable Diseases. Revista Brasileira de Enfermagem, 71(Suppl 6), 2643-9. Recuperado de http://www.scielo.br/pdf/ reben/v71s6/pt_0034-7167-reben-71-s6-2643.pdf. doi: 10.1590/0034-7167-2017-0799

Crema, E., \& Silva, E. (1997). Estomas: uma abordagem interdisciplinar. Uberaba: Editora Pinti.

Dejours, C. (2001). Le corps d'abord. Paris: Petite Bibliotheque Payot.

Freud, S. (1901/1905). Fragmento da análise de um caso de histeria. In: J. Salomão (Org.). Edição standard brasileira das obras psicológicas completas de Sigmund Freud (v. VII). Rio de Janeiro: Imago.

Freud, S. (1913). Sobre o início do tratamento. In: J. Salomão. (Org.). Edição standard brasileira das obras psicológicas completas de Sigmund Freud (v. XII). Rio de Janeiro: Imago.

Freud, S. (1923) O Ego e o Id. In: J. Salomão (Org.). Edição standard brasileira das obras psicológicas completas de Sigmund Freud (v. XII). Rio de Janeiro: Imago.

Freud, S. (1925). A negativa. In: J. Salomão. (Org.). Edição standard brasileira das obras psicológicas completas de Sigmund Freud (v. XIX). Rio de Janeiro: Imago.

Furegato, A. R. F. (2018). Políticas de saúde mental e abertura para o futuro. Revista Baiana de Enfermagem, 32(1),1-3. Recuperado de https://portalseer.ufba.br/index.php/ enfermagem/article/view/27578/16911. doi: 10.18471/rbe. $\underline{\mathrm{v} 32.27578}$

Garcia, A. C. M., Simão-Miranda, T. P., Carvalho, A. M. P., Elias, P. C. L., Pereira, M. G., ... Carvalho, E. C. (2018). The effect of therapeutic listening on anxiety and fear among surgical patients: randomized controlled trial. Revista Latino-Americana de Enfermagem, 26, e3027. Recuperado de: http://www.scielo.br/pdf/rlae/v26/pt_0104-1169-rlae26-e3027.pdf. doi: 10.1590/1518-8345.2438.3027

Laplanche, J. (2001). Vocabulário da Psicanálise: Laplanche e Pontalis. São Paulo: Martins Fontes. 
Macêdo, S., Souza, G. W. S., \& Lima, M. B. A. (2018). Oficina de desenvolvimento da escuta: prática clínica na formação em psicologia. Revista da Abordagem Gestáltica, 24(2), 123133. Recuperado de http://pepsic.bvsalud.org/pdf/rag/ v24n2/v24n2a02.pdf. doi: 10.18065/RAG.2018v24n2.1

Martins, F. M. M. C. (2005). Psicophatologia I: Prolegômenos. Belo Horizonte: Pucminas.

Mirand, S. M., Nascimento, C. M. F. S., Luz, M. H. B. A., Andrade, E. M. L. R., Luz, A. L. A., ... Torres, C. R. D. (2014). Viver com Estomia: Contribuições para a Assistência de Enfermagem. Revista Brasileira de Terapia Enterostomal - Revista Estima, 12(3). Recuperado de https://www.revistaestima.com.br/ index.php/estima/article/view/94

Michaelis (1998). Moderno dicionário da língua portuguesa. São Paulo: Companhia Melhoramentos.

Minayo, M. C. (2014). O desafio do conhecimento: Pesquisa qualitativa em saúde. São Paulo: Hucitec.

Oliveira, M. B. P., Souza, N. R., Bushatsky, M., Dâmaso, B. F. R., Bezerra, D. M., ... Brito, J. A. (2017). Atendimento domiciliar nos cuidados paliativos. Escola Anna Nery, 21(2). Recuperado de: http://www.scielo.br/pdf/ean/v21n2/14148145-ean-21-02-e20170030.pdf . doi: 10.5935/1414$\underline{8145.20170030}$

Resolução CNS $n^{\circ} 466$, de 12 de dezembro 2012. Recuperado de: https://conselho.saude.gov.br/resolucoes/2012/Reso466. pdf

Weizsäcker, V. (1958). Le Cyrle de La Structure. Paris: Desclée de Brouwer. 